\title{
DELPHINE AEBI, Le scandale au théâtre des années 1940 aux années 1960
}

\section{Paola Perazzolo}

\section{OpenEdition}

\section{Journals}

\section{Edizione digitale}

URL: https://journals.openedition.org/studifrancesi/32228

DOI: 10.4000/studifrancesi.32228

ISSN: 2421-5856

\section{Editore}

Rosenberg \& Sellier

\section{Edizione cartacea}

Data di pubblicazione: 1 août 2020

Paginazione: 439-440

ISSN: 0039-2944

\section{Notizia bibliografica digitale}

Paola Perazzolo, "DELPHINE AEBI, Le scandale au théâtre des années 1940 aux années 1960», Studi Francesi [Online], 191 (LXIV | II) | 2020, online dal 01 septembre 2020, consultato il 18 septembre 2021. URL: http://journals.openedition.org/studifrancesi/32228; DOI: https://doi.org/10.4000/studifrancesi. 32228

Questo documento è stato generato automaticamente il 18 septembre 2021.

\section{(c) (i) ()}

Studi Francesi è distribuita con Licenza Creative Commons Attribuzione - Non commerciale - Non opere derivate 4.0 Internazionale. 


\title{
DELPHINE AEBI, Le scandale au théâtre des années 1940 aux années 1960
}

\author{
Paola Perazzolo
}

\section{NOTIZIA}

DELPHINE AEBI, Le scandale au théâtre des années 1940 aux années 1960, Paris, Champion, 2017, $421 \mathrm{pp}$.

1 Tratto da una tesi di dottorato discussa nel 2011, il volume in oggetto prende in considerazione le modalità di presentazione e ricezione di numerose pièces messe in scena tra il 1940 e il 1960 che hanno suscitato forti discussioni e polemiche e provocato, appunto, degli scandali teatrali. Il periodo preso in esame, marcato dal secondo conflitto mondiale e da importanti tensioni a livello politico e sociale che rimettono in discussione i concetti stessi di alterità e di identità, sembra da questo punto di vista particolarmente propizio al sorgere di contestazioni, così come il genere scelto, la cui dimensione pubblica è allo stesso tempo potenzialmente conflittuale e fortemente spettacolare. Concetto proteiforme qui non considerato da un punto di vista morale ossia implicante una condanna o una celebrazione dell'evento e/o dello spettacolo portatore di una trasgressione morale, ideologica, estetica o politica rispetto alla doxa coeva-, lo scandalo teatrale viene piuttosto esaminato come un mezzo che i drammaturghi usano per imporsi con forza ed éclat e come possibilità di instaurare una «communication privilégiée [...], offrant l'espoir d'un théâtre capable de concilier l'individu et la cité» (quarta di copertina).

2 Sia esso ricercato, rivendicato, celebrato e anche teorizzato - è il caso di Cocteau e Aymé -, sia esso subito e condannato, lo scandalo provocato da spettacoli di autori tutti celebri ma diversissimi tra loro per età, convinzioni estetiche, etiche e/o politiche, provenienza geografica, assume diverse forme e modalità e non riguarda solo scrittori appartenenti alle cosiddette avanguardie o rappresentati in sale poco istituzionali - per citare solo uno tra i casi più noti, il contestatissimo Les paravents di Genet fu messo in 
scena nel 1966 al Théâtre de l'odéon, tempio della drammaturgia parigina. Il corpus analizzato comprende infatti opere dei già citati Aymé, Cocteau e Genet, oltre che degli altri principali protagonisti della produzione drammatica coeva quali Ghelderode, Montherlant, Sartre, Camus, Ionesco, Beckett, Vian, Anouilh, Giraudoux, Arrabal, Césaire, Yacine e altri, di cui l'A. evoca e illustra le provocazioni a livello morale, religioso, politico, sociale ed estetico rivolte a spettatori considerati talvolta come dei borghesi da épater, talvolta come dei complici ideali. Benché la vastità e l'eterogeneità del corpus impedisca a volte di seguire agevolmente l'argomentazione proposta, il volume presenta un panorama della produzione drammatica di un'epoca non solo di crisi e di tensioni politiche e sociali ma anche di grande fermento a livello di innovazioni poetiche. Elementi, questi ultimi, che concorrono fortemente a suscitare contestazioni e a forgiare uno scandalo che «révèle [...] le désir d'un échange entre la salle et la scène, au point de devenir un mode de communication particulièrement adapté à une époque instable, en crise. La provocation constitue davantage un appel qu'une agression» (p. 396). 